\title{
Stimulus pulse number effect on lingual vibrotactile thresholds
}

\author{
LINDA PETROSINO \\ University of North Carolina, Chapel Hill, North Carolina \\ and \\ DONALD FUCCI and ELISE McMATH \\ Ohio University, Athens, Ohio
}

\begin{abstract}
The present pilot investigation was designed to study the effects of pulse number on lingual vibrotactile thresholds when two different contactor sizes were employed. The results suggested that a temporal summation effect occurs with an increase in pulse repetition rate and contactor size. These findings are indicative of a need for future work involving summation measures as a basis for investigating the neurological integrity of the lingual sensory system.
\end{abstract}

Within the past few decades, the absolute threshold for both electrocutaneous stimulation and mechanical vibration of human cutaneous tissue has been investigated using various temporal patterns of the employed stimulus (Fucci, Arnst, \& Telage, 1972; Higashiyama \& Tashiro, 1983; McCall, 1972; Telage, Fucci, \& Blackmon, 1976; Verrillo, 1965, 1966). Verrillo (1965) determined that vibrotactile thresholds decreased with increasing stimulus durations up to approximately $600 \mathrm{msec}$. In 1966, Verrillo determined taction thresholds for short pulses with different repetition rates and contactor sizes. Summation of energy was observed across pulse rate for the larger contactors $\left(.32 \mathrm{~cm}^{2}\right.$ and $\left.2.9 \mathrm{~cm}^{2}\right)$, but no summation occurred for the smaller contactors $\left(.02 \mathrm{~cm}^{2}\right.$ and $\left..005 \mathrm{~cm}^{2}\right)$. McCall (1972) demonstrated the presence of temporal summation for supraliminal electrocutaneous stimuli of different pulse durations applied to the tongue. He suggested that for electrocutaneous stimuli, the mechanism underlying the process of temporal summation for pulse duration may differ from the mechanism underlying the process of temporal summation for pulse number. Telage, Fucci, and Blackmon (1976) studied lingual vibrotactile thresholds for stimulus durations of $50-400 \mathrm{msec}$, and showed that a temporal summation function occurred within that time span. More recently, Higashiyama and Tashiro (1983) studied temporal and spatial integration for electrocutaneous stimulation of the wrist and palmar surface at absolute threshold level. Their results led to the conclusion that duration of pulse and separation of electrodes are the most crucial variables for electrocutaneous sensitivity.

L. Petrosino's mailing address is: Division of Speech and Hearing Sciences, University of North Carolina at Chapel Hill, 76 Wing D Medical School, 208H Chapel Hill, NC 27514.
These previous experiments have shown that tactile receptors exhibit a consistent summation response (Zwislocki, 1960). Compared with information collected from other sense modalities, the data on temporal integration for lingual mechanoreception are not very extensive. The present pilot investigation was designed to study, using two different contactor sizes, the effects of pulse number on lingual vibrotactile thresholds.

\section{METHOD}

\section{Subjects}

Twenty undergraduate students were selected randomly from a group of 88 students enrolled in an introductory speech and hearing course. The age range for the group of subjects was 18-26 years (mean age $=19.6$ years). All subjects had normal speech and hearing and reported no known sensory and/or motor impairments. None of the subjects had prior experience with vibrotactile threshold testing or was familiar with the instrumentation used in this study.

\begin{abstract}
Apparatus
The vibrotactile instrumentation consisted of a stimulus unit and a measurement unit. The stimulus unit was composed of a signal pulse generator and various Coulbourn logic modules capable of generating a vibratory signal varying in frequency, intensity, and temporal characteristics. The signal delivered from the stimulus unit drove an electromagnetic minivibrator with a probe-contactor extension. The vibratory signal consisted of a series of $1 \mathrm{msec}$ squarewave pulses. The measurement unit included an accelerometer, a cathode follower, a microphone amplifier, and a voltmeter. A narrow band noise generator was used to present auditory masking at $70 \mathrm{db}$ HL to the subjects in order to prevent them from hearing the vibratory pulses being presented.
\end{abstract}

\section{Procedure}

Each subject was required to attend two experimental sessions in order to minimize subject fatigue and/or test site sensory adaptation. In each session, the subject was seated in an adjustable chair and asked to place his/her tongue flat against the underside of a rigidly mounted plastic disk. A hole in the center of the disk al- 
lowed for the vibrator probe-contactor extension to come into contact with the lingual dorsal surface.

Subjects received training prior to threshold data collection in order to become acquainted with the nature of the stimulus and the testing apparatus. Training was performed on the tip of the right index finger with a pulse repetition rate of 12 pulses per second (pps). The size of the contactor used for training was $.128 \mathrm{~cm}^{2}$.

The method of limits was used to obtain lingual vibrotactile thresholds. Individual lingual threshold measurements were acquired for seven pulse repetition rates $(2,4,8,16,32,64$, and $128 \mathrm{pps})$ for each of two different contactor sizes $\left(.128 \mathrm{~cm}^{2}\right.$ and $\left.1.30 \mathrm{~cm}^{2}\right)$. Order of presentation of the seven pulse repetition rates was randomized and order of presentation of the two contactor sizes was counterbalanced for all subjects. Subjects were required to respond by raising their hands when they first detected the pulsed vibratory stimulus on the lingual dorsal surface. A mean of $3 \mathrm{mV}$ readings per pulse repetition rate and contactor size was accepted as lingual threshold. The millivolt readings were converted to displacement in decibels re 1 micron peak to peak.

\section{RESULTS AND DISCUSSION}

The lingual vibrotactile threshold results shown in Figure 1 are plotted as a function of pulse repetition rate for the two contactor sizes. Each data point represents the mean of the thresholds collected for the 20 subjects. It appears that the lingual tactile receptors showed summation of energy as pulse rate was increased. A reduction in the energy summation was apparent for the higher pulse repetition rates of 64 and 128 pps. There also was a difference in thresholds for the two contactors employed. Thresholds obtained with the larger contactor $\left(1.30 \mathrm{~cm}^{2}\right)$ were slightly lower.

The results of this study are similar to those of Verrillo $(1963,1966)$. He studied thresholds of the palmar

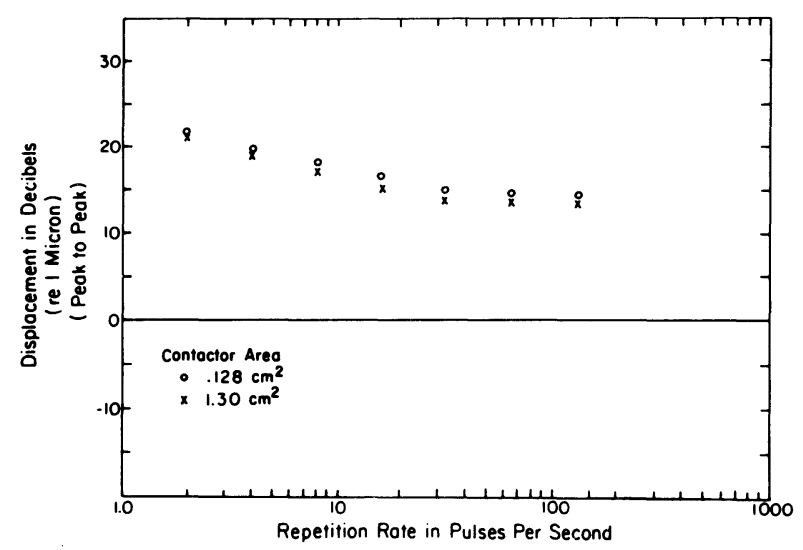

Figure 1. Lingual vibrotactile thresholds as a function of pulse repetition rate with contactor area as a parameter. surface for short pulses. The palmar surface thresholds showed no summation over pulse repetition rate for small contactors $\left(.02 \mathrm{~cm}^{2}\right.$ and $\left..005 \mathrm{~cm}^{2}\right)$, but there was a difference in threshold response for the larger contactors $\left(.32 \mathrm{~cm}^{2}\right.$ and $\left.2.9 \mathrm{~cm}^{2}\right)$. The differences in contactor sizes employed for the present study and for those conducted by Verrillo $(1963,1966)$ make direct comparisons of slope differences between the two investigations impossible. In the present study, the largest contactor used was $1.30 \mathrm{~cm}^{2}$, which was less than one half the size of the largest contactor of $2.9 \mathrm{~cm}^{2}$ used by Verrillo. It is likely that the small contactors typically used to accommodate the lingual structure did not stimulate enough of the summating receptors within the tongue to create a sharp summating response like those reported by Verrillo $(1963,1966)$. The use of a larger contactor would probably have brought the summating response found on the lingual dorsal surface to a more definitive temporal summation slope.

The data generated from this study suggest that the tactile receptors can make temporal discriminations with respect to lingual tactile stimuli of varying pulse number, if the size of the contactor is large enough to allow that response to take place. Temporal summation is considered to be an integrative measure (Zwislocki, 1960) and, therefore, may be utilized as an indicator of normal functional integrity of a particular tactile sensory system such as that of the tongue. These preliminary findings encourage future study to attempt to identify threshold patterns or characteristics that may be used to differentiate normal from abnormal lingual tactile sensory system processing.

\section{REFERENCES}

Fucci, D., Arnst, D., \& Telage, K. (1972). The effects of pulsed and continuous stimulation on vibrotactile thresholds obtained from the tongue. Bulletin of the Psychonomic Society, 29, 83-84.

Higashiyama, A., \& TASHiro, T. (1983). Temporal and spatial integration for electrocutaneous stimulation. Perception \& Psychophysics, 33, 437-442.

MCCALL, G. (1972). Duration effects of supraliminal electrical stimuli to the tongue. Journal of Speech \& Hearing Research, 15, 869-875.

Telage, K., FucCI, D., \& Blackmon, R. (1976). Temporal summation effects on lingual vibrotactile thresholds. Perceptual \& Motor Skills, 42, 859-864.

VERRLLLO, R. T. (1963). Effect of contactor area on the vibrotactile threshold. Journal of the Acoustical Society of America, 35, 1962-1966.

Verrillo, R. T. (1965). The effect of number of pulses on vibrotactile thresholds. Psychonomic Science, 3, 73-74.

Verrillo, R. T. (1966). Taction thresholds for short pulses. Psychonomic Science, 4, 409-410.

ZWISLOCKI, J. (1960). Theory of temporal summation. Journal of the Acoustical Society of America, 32, 1046-1060.

(Manuscript received for publication March 25, 1985.) 